\title{
Comparison of analogue antenna downlinks via coaxial cable and optical fibre in terms of mechanical and environmental stability
}

\author{
T. Berenz ${ }^{1}$, F. Perini ${ }^{2}$, and G. Bianchi ${ }^{2}$ \\ ${ }^{1}$ Max-Planck-Institut fuer Radioastronomie (MPIfR), Auf dem Huegel 69,53121 Bonn, Germany \\ e-mail: tberenz@mpifr-bonn.mpg.de \\ 2 I.N.A.F. - I.R.A, Via Fiorentina, 3508/B 40059 - Medicina, Italy* \\ e-mail: f.perini@ira.inaf.it, g.bianchi@ira.inaf.it
}

\begin{abstract}
The transmission characteristics of analogue optical fibres change if the fibre is bended or twisted. This happens if they are used as downlink in steerable antennas. These mechanical stresses and the changes of the environmental temperature, pressure, etc. leads to instabilities of phase and gain of the transmitted signals. To compare these effects two measurement campaigns have been done at both the Effelsberg (Germany) and Medicina (Italy) antennas. A dedicated optical rack, composed by a couple of optical TX and RX pairs, was set up and accurately characterized in laboratory due to the high sensitivity needed for the measurements. An ad hoc automated measurement system has been set up. This allowed to control and collect data from all the instrumentation and merging them with the acquired environmental parameters and antenna pointing. Beside these, also environmental temperature changes affect the signal. This paper describes the amplitude and phase behaviour of this transmitted signal and compares this with the behaviour of a normal coaxial cable.
\end{abstract}

\section{Introduction}

Transmitting broadband RF/IF signals above long distances is a big problem due to the high attenuation of the coaxial cables. This problem can be resolved, when optical fibres, which only have an attenuation of about $0.2 \mathrm{~dB} / \mathrm{km}$ are used instead of the normally adopted coaxial cables. The RF/IF signal is then used to modulate the optical power of the laser source. A problem, which could arise when using this technique, are the environmental influences as well as mechanical stresses to the fibre due to twisting and bending, especially for downlink of the steerable antenna. Both effects influence the transmission in phase and gain. So, a comparison between a normally used coaxial cable and a fibre optic link was necessary. For this reason we made two measurement campaigns at the radio telescopes in Effelsberg, Germany and in Medicina, Italy. This work falls in the SKADS DS3-T1 task and could be a useful input to PrepSKA WP2 STaN too, since the choice of the signal transportation system (digital or analogue, coaxial or fibre, etc.) for the SKA antennas is under study.

\section{Measurement setup}

The measurement principle is shown in Figure 1. A vector network analyser (HP8751A) has been employed to measure simultaneously the phase and the gain of both the optical link and the coaxial cable. Both where chosen to be a loop from the control room to the antenna (primary focus cabin or secondary focus cabin of the telescope) and back. The optical transmitter and receiver were located in a single, temperature isolated rack

* This work was supported by the European Commission Framework Program 6, Project SKADS, Square Kilometre Array Design Studies (SKADS), contract no 011938.

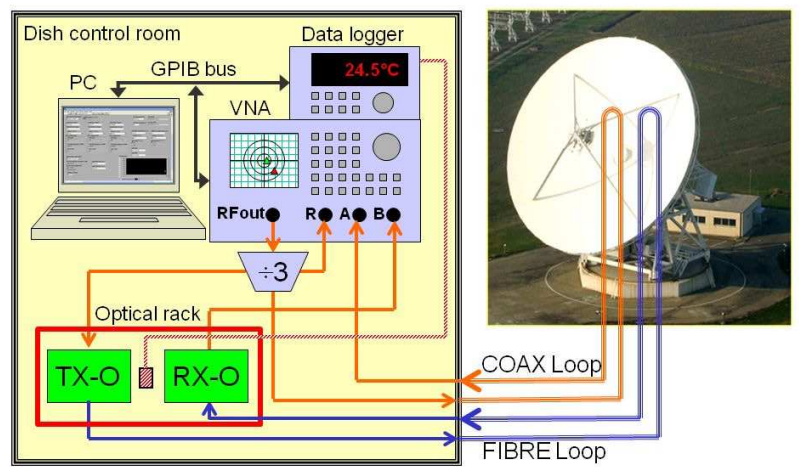

Fig. 1: Block diagram of the used measurement system

(optical rack). Due to the high sensitivity required for the measurements (i.e. less than $0.01 \mathrm{~dB}$ for amplitude measurements), rack temperature as well as room temperature are acquired also in order to monitor their effects on the measured data. The complete measurement system is controlled via GPIB bus with a Labview(c) frontend software.

\subsection{Electro optical devices}

For the measurement a prototype transmitter TDX300 from "Andrew Wireless Solutions" equipped with a thermoelectric cooler (TEC) was used. The transmission wavelength is $1300 \mathrm{~nm}$ with an optical output power of about $+6 \mathrm{dBm}$. The receiver TFRY501 is also from "Andrew Wireless Solutions". It is a passive device, which only consists of the detector diode and a $50 \Omega$ termination resistor. The working wavelength is 


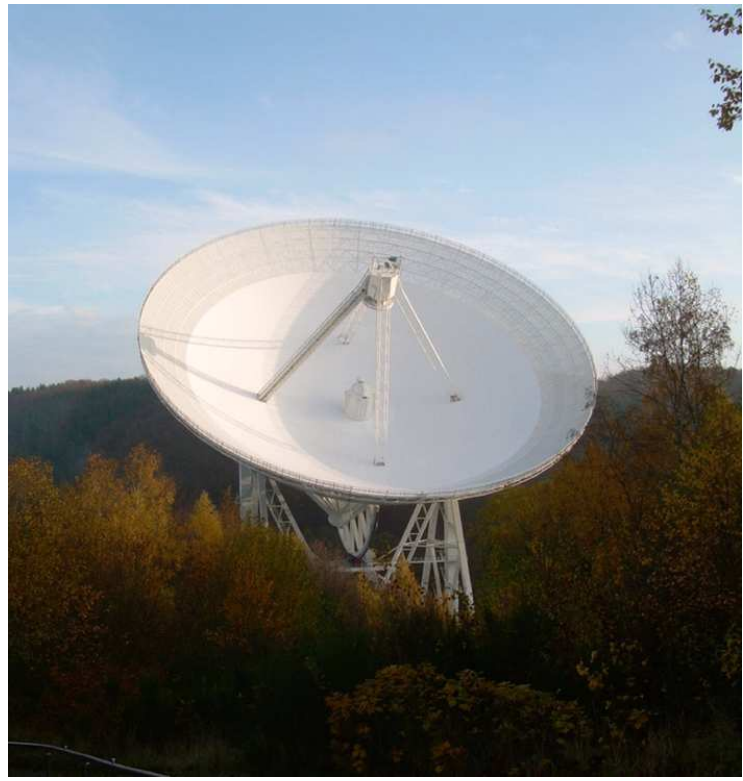

Fig. 2: Effelsberg radio telescope

between $1200 \mathrm{~nm}$ to $1600 \mathrm{~nm}$ with a maximum optical input power of $+10 \mathrm{dBm}$.

\subsection{The antenna downlinks investigated}

The antennas investigated were the $100 \mathrm{~m}$ Effelsberg radio telescope, in Germany (see Figure 2), and the $32 \mathrm{~m}$ Medicina dish, in Italy (Figure 3). For both antennas, the optical downlink consists of an all dielectric gel filled monotube loose cable, with 12 standard singlemode fibres. The antenna fibre downlink investigated go from the primary focus to the Faraday room for Effelsberg, (total length $380 \mathrm{~m}$ ), and from the secondary focus to the receiver room, for Medicina (total length $100 \mathrm{~m}$ ).

\section{Results}

\subsection{Effelsberg measurements}

Several measurements have been done in the Effelsberg telescope. As the results are comparable, only one measurement will be discussed here. Table 1 shows the particular results of the other measurements.

Figure 4 and Figure 5 show the result of the measurements in the Effelsberg telescope. The vertical dashed lines separate the diagrams in three different parts. In the first one (left) the telescope is not moving as well as in the last one (right). In the middle some astronomical measurements where done. Except to the first, all other diagrams are plotted with removed offset, which means that they are scaled to the maximum.

The upper diagram in Figure 4 shows the azimuth and the elevation angle of the telescope. The second diagram in this figure shows the acquired temperatures in the faraday room and in the optical rack. The oscillations of the room- and rack temperatures are due to the air-conditioning system. The outside

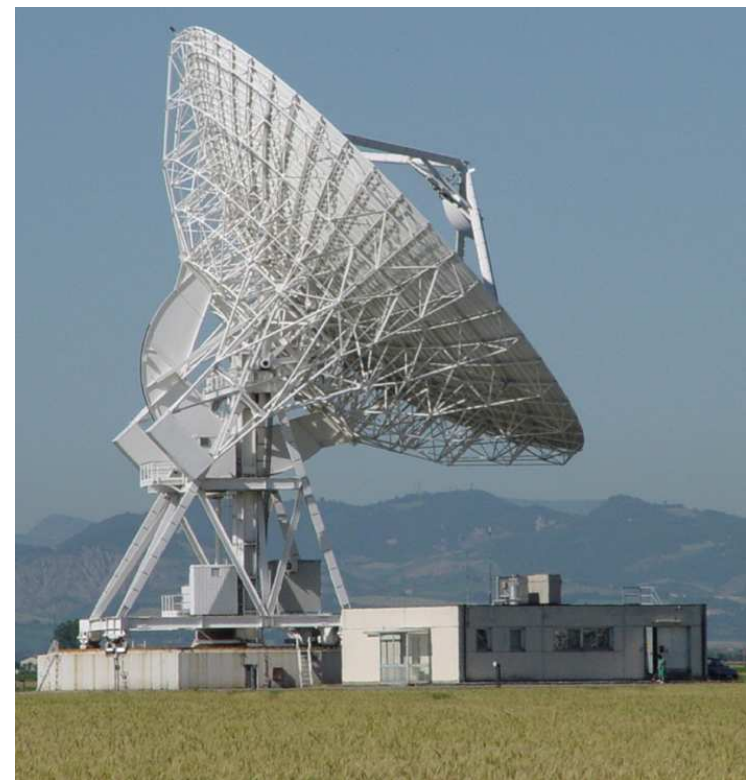

Fig. 3: Medicina VLBI antenna
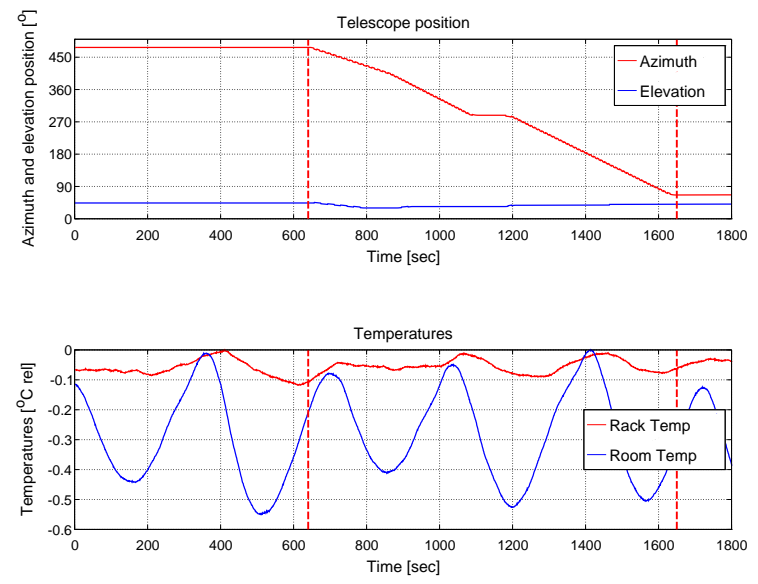

Fig. 4: Telescope position with room and rack temperature. In the left part and in the right part (separated by the dashed lines) the telescope is standing still, while in the middle part the telescope is moving.

temperature can be stated to be constant during the measurement.

In Figure 5 the upper diagram shows the gain of the coaxial cable and the optical fibre. It is obvious that the variations of the coaxial cable due to the room temperature are much higher than these of the optical fibre while the telescope is standing still. This behaviour does not change when the telescope is moving. The gain of the fibre changes about $0.06 \mathrm{~dB}$ while the coaxial cable behaves twice as worse.

The second diagram in the figure shows the phase behaviour of the cables. As well as in the forgoing diagram the fibre behaves better than the coaxial cable, especially while the telescope is moving. 

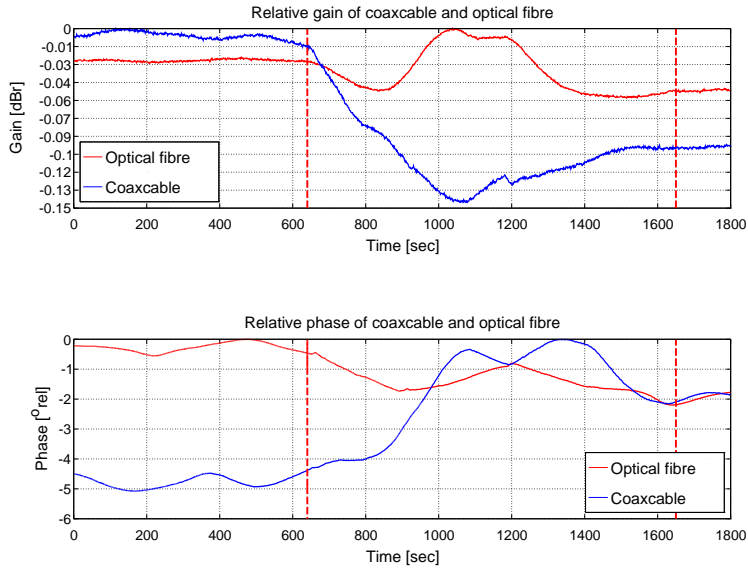

Fig. 5: This diagram depends to Figure 4. Here the gain and phase of the optical fibre and the coaxial cable are shown.
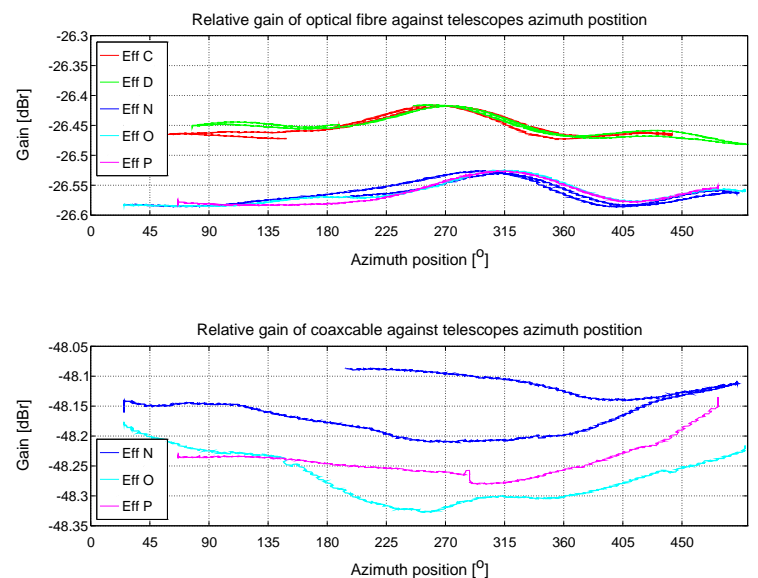

Fig. 6: The upper diagram shows different the gain measurements of the optical fibres in relation to the telescopes azimuth position. It is obvious that the fibres show repeatable behaviour. The offset between the two curves are due to reconnection of the fibre loop. The lower diagram shows the gain behaviour of the coaxial cable.

Figure 6 shows the gain of the coaxial cable and the optical fibres in relation to the telescopes azimuth position. Several measurements with the fibres have been made and are plotted in the upper diagram. It is obvious that the fibres show repeatable behaviour. The offset between the two curves are due to reconnection of the fibre loop.

The lower diagram shows the gain of the coaxial cable. There is no repeatability in the behaviour although the loop was not reconnected between the different measurements.

\subsection{Medicina measurements}

In Medicina three different measurement campaigns have been done. The first and the second one were done, respectively, in late November 2008 and mid August 2009, without the antenna motion control. These measurements consisted in several snapshots, each 4 hours long, taken in piggy back mode during astronomical observations. The third measurement campaign was done in mid October 2009 with the antenna motion control. In this case an ad hoc antenna schedule, about 8 hours long, has been created. The main aspect resulting from the Medicina measurements is the dominant factor on the antenna downlinks, both coax and fibre cable, is the external temperature. Both azimuth and elevation movements are perceptible with similar effects on both downlinks. That clearly results from Figure 7 where two acquisitions are compared. Both were done the same day but with different external temperature conditions.

\section{Conclusion}

As a result of these measurements it can be stated, that analogue transmission via optical fibres behaves better than via coaxial cables. The mechanical stress due to twisting and bending mainly leads to gain changes while temperature effects mainly effect the phase of the transmitted signal. These varit ations can also be measured in the signal of the coaxial cable. Here the effects are about twice as high than in the optical fibre So in any case the fibre behaves better than the coaxial cables which means that we could strongly suggest these transmission systems for broadband analogue downlinks.

Acknowledgements. The authors are grateful to Ing. Pier Faccin (Andrew Wireless Systems), who provided the optical transmitter equipped with TEC module used for the measurements. 
Table 1: Results of the measurements at the radio telescope Effelsberg

\begin{tabular}{|c|c|c|c|c|c|c|c|c|c|c|c|}
\hline \multirow[b]{3}{*}{ Meas } & \multirow{2}{*}{\multicolumn{2}{|c|}{$\begin{array}{c}\text { Antenna } \\
\text { movements }\end{array}$}} & \multirow{3}{*}{$\begin{array}{l}\text { Dur- } \\
\text { ation } \\
(\mathrm{min})\end{array}$} & \multicolumn{4}{|c|}{ Optical fibre } & \multicolumn{4}{|c|}{ Coax cable } \\
\hline & & & & \multirow{2}{*}{$\begin{array}{c}\text { Max } \\
\text { variation } \\
(\mathrm{dB})\end{array}$} & \multirow{2}{*}{$\begin{array}{c}\text { Mean } \\
\text { variation } \\
( \pm \mathrm{dB})\end{array}$} & \multirow{2}{*}{$\begin{array}{c}\text { Max } \\
\text { variation } \\
(\mathrm{deg})\end{array}$} & \multirow{2}{*}{$\begin{array}{c}\text { Mean } \\
\text { variation } \\
( \pm \text { deg })\end{array}$} & \multirow{2}{*}{$\begin{array}{c}\text { Max } \\
\text { variation } \\
(\mathrm{dB})\end{array}$} & \multirow{2}{*}{$\begin{array}{c}\text { Mean } \\
\text { variation } \\
( \pm \mathrm{dB})\end{array}$} & \multirow{2}{*}{$\begin{array}{c}\text { Max } \\
\text { variation } \\
(\mathrm{deg})\end{array}$} & \multirow{2}{*}{$\begin{array}{c}\text { Mean } \\
\text { variation } \\
( \pm \mathrm{deg})\end{array}$} \\
\hline & $\begin{array}{c}\mathrm{Az} \\
(\mathrm{deg})\end{array}$ & $\begin{array}{c}\text { Ev } \\
\text { (deg) }\end{array}$ & & & & & & & & & \\
\hline $\begin{array}{l}\text { uncer- } \\
\text { tainty }\end{array}$ & \multicolumn{2}{|c|}{$\begin{array}{l}\text { No } \\
\text { loop }\end{array}$} & 15 & 0.0038 & 0.0019 & 0.0707 & 0.0354 & - & - & - & - \\
\hline \multirow{4}{*}{$\begin{array}{c}\text { Still } \\
\text { antenna }\end{array}$} & $\overline{\text { No }}$ & No & \multirow[b]{2}{*}{2} & \multirow[b]{2}{*}{0.0020} & \multirow[b]{2}{*}{0.0010} & \multirow[b]{2}{*}{0.6695} & \multirow[b]{2}{*}{0.3348} & \multirow[b]{2}{*}{0.0211} & \multirow[b]{2}{*}{0.0106} & \multirow[b]{2}{*}{0.6517} & \multirow[b]{2}{*}{0.3259} \\
\hline & 25 & 88 & & & & & & & & & \\
\hline & No & No & \multirow[b]{2}{*}{11} & \multirow[b]{2}{*}{0.0052} & \multirow[b]{2}{*}{0.0026} & \multirow[b]{2}{*}{0.5528} & \multirow[b]{2}{*}{0.2764} & \multirow[b]{2}{*}{0.0145} & \multirow[b]{2}{*}{0.0073} & \multirow[b]{2}{*}{0.6274} & \multirow[b]{2}{*}{0.3137} \\
\hline & 477 & 44 & & & & & & & & & \\
\hline & $\overline{\text { Yes }}$ & No & & & & & & & & & \\
\hline & $25-492$ & 88 & 43 & 0.0607 & 0.0303 & 3.6773 & 1.8387 & 0.1248 & 0.0624 & 5.1732 & 2.5866 \\
\hline Only & Yes & No & & & & & & & & & \\
\hline & $194-492$ & 88 & 16 & 0.0546 & 0.0273 & 1.6528 & 0.8264 & 0.0546 & 0.0273 & 1.4730 & 0.7365 \\
\hline & Yes & No & & & & & & & & & \\
\hline azimuth & $492-25$ & 88 & 25 & 0.0607 & 0.0303 & 1.3856 & 0.6928 & 0.1011 & 0.0506 & 4.9968 & 2.4964 \\
\hline & Yes & No & & & & & & & & & \\
\hline & $25-498$ & 88 & 20 & 0.0606 & 0.0303 & 1.6334 & 0.8167 & 0.1506 & 0.0753 & 3.9624 & 1.9812 \\
\hline & Yes & Yes & & & & & & & & & \\
\hline Both & $47-477$ & $30-46$ & 30 & 0.0580 & 0.0290 & 2.2000 & 1.1000 & 0.1451 & 0.0726 & 5.0798 & 2.5399 \\
\hline angles & Yes & Yes & & & & & & & & & \\
\hline & $47-477$ & $30-46$ & 19 & 0.0580 & 0.0290 & 1.7758 & 0.8879 & 0.1317 & 0.0659 & 4.4519 & 2.2260 \\
\hline
\end{tabular}
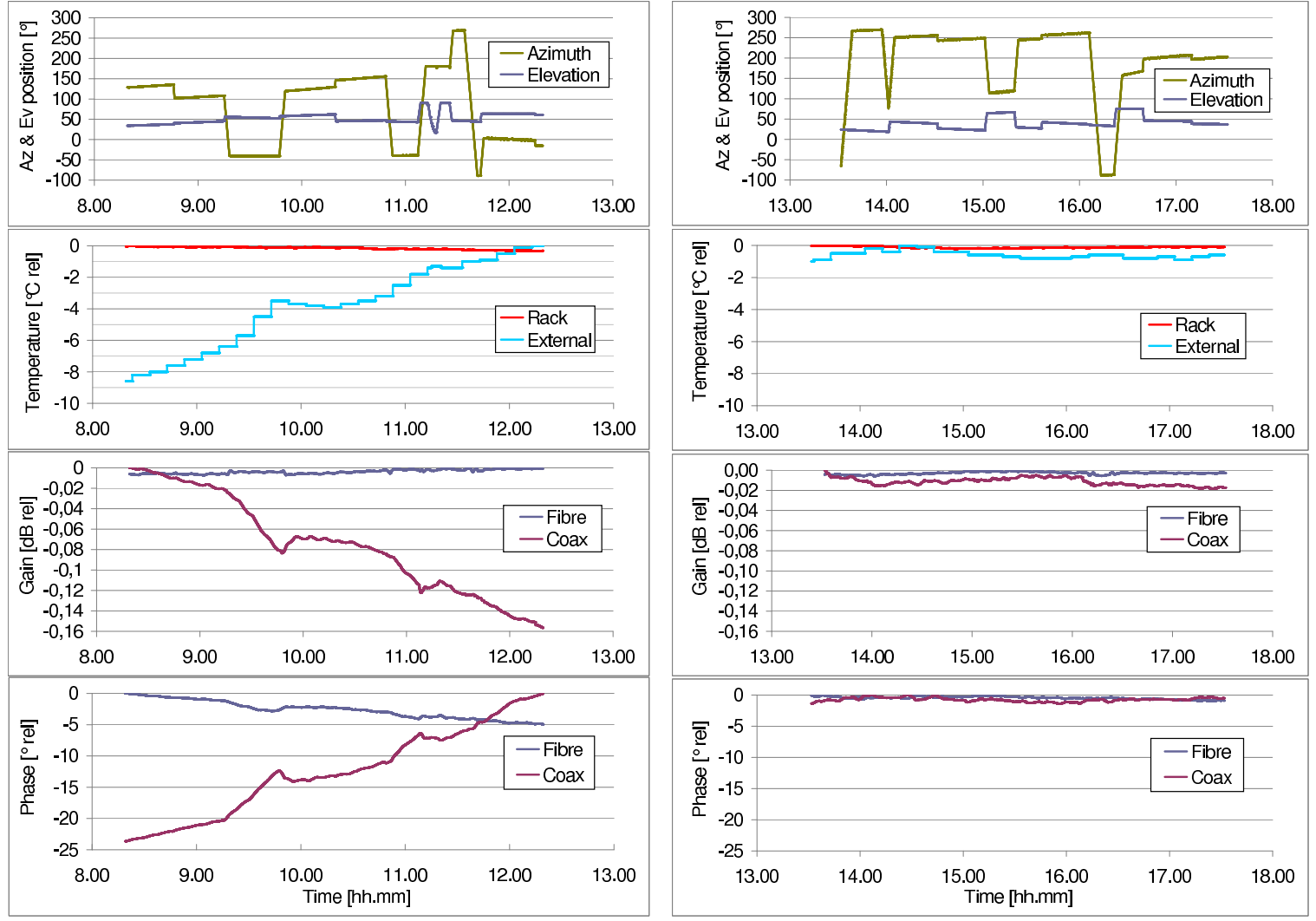

Fig. 7: Medicina measurements on August, the $19^{\text {th }} 2009$. Left side: external temperature moved from $24{ }^{\circ} \mathrm{C}$ to $34{ }^{\circ} \mathrm{C}$; right side external temperature quite still at $34.5^{\circ} \mathrm{C}$. 